Published in final edited form as:

J Allergy Clin Immunol Pract. 2017 ; 5(3): 855-857.e1. doi:10.1016/j.jaip.2016.10.004.

\title{
Comparison of Treatment Modalities for Inpatient Asthma Exacerbations among U.S. Pediatric Hospitals
}

\author{
Meredith. A. Dilley, MD ${ }^{1,2}$, William. J. Sheehan, MD ${ }^{1,2}$, Carter R. Petty, MS ${ }^{1}$, Jonathan $\mathbf{M}$. \\ Gaffin, MD, MMSc ${ }^{1,2}$, Marissa Hauptman, MD, MPH ${ }^{1,2}$, and Wanda Phipatanakul, MD, MS ${ }^{1,2}$ \\ ${ }^{1}$ Boston Children's Hospital, Boston, MA \\ ${ }^{2}$ Harvard Medical School, Boston, MA
}

\section{Summary}

When comparing treatment for inpatient pediatric asthma hospitalizations, there is significant variability in treatment with magnesium sulfate, ipratropium bromide, terbutaline, heliox, BiPAP, and mechanical ventilation for PICU admissions across U.S. pediatric hospitals.

\section{Keywords}

Asthma; pediatric; corticosteroid; beta 2 -agonist; terbutaline; magnesium; helium oxygen; oxygen; BiPAP; intubation; mechanical ventilation; PICU

\section{To the Editor}

Asthma is a leading cause of hospitalization in children. ${ }^{1,2}$ Known risk factors for asthma exacerbations include demographic factors, atopic status, second-hand smoke exposure, and obesity. ${ }^{3-5}$ Frontline therapies to treat an acute asthma exacerbation include corticosteroids and bronchodilators. ${ }^{6,7}$ Guidelines for the management of asthma, including outpatient exacerbations, have been widely promoted in the U.S. and Europe. The Global Initiative for Asthma (GINA) published guidelines in 2015 for asthma management in children and adults. ${ }^{6}$ These guidelines include recommendations for inpatient care, specifically shortacting beta 2 -agonist, oxygen, and corticosteroids for moderate to severe exacerbations, and consideration of other therapies for those unresponsive to frontline therapies. ${ }^{6}$ However, many hospitals develop local evidence and experience-based asthma pathways to treat asthma, ${ }^{8}$ particularly in the intensive care setting, which may reflect the paucity of data related to effective inpatient management.

Corresponding Author: Wanda Phipatanakul, M.D. M.S., 300 Longwood Avenue, Fegan 6, Boston, MA, 02116. T: (617)355-6117; F: (617)730-0310; wanda.phipatanakul@ childrens.harvard.edu.

Conflict of Interest: None

Publisher's Disclaimer: This is a PDF file of an unedited manuscript that has been accepted for publication. As a service to our customers we are providing this early version of the manuscript. The manuscript will undergo copyediting, typesetting, and review of the resulting proof before it is published in its final citable form. Please note that during the production process errors may be discovered which could affect the content, and all legal disclaimers that apply to the journal pertain. 
While it has been suggested that pediatric intensive care unit (PICU) level care for pediatric asthma may have regional variation, ${ }^{9}$ the variation between pediatric hospitals across the U.S. has not been examined. We aimed to determine the treatment variation for asthma in PICUs among U.S. pediatric hospitals using a nation-wide claims database of pediatric hospitals.

We evaluated inpatient hospitalizations to the PICU for asthma using the Pediatric Health Information System (PHIS) Database, a multi-institutional database that includes data collected from inpatient admissions and emergency department visits from 43 free-standing U.S. children's hospitals spread across the geographic United States. Forty hospitals were included in the analysis; hospitals without inclusive data for the time period queried were excluded. We queried discharge data from January 2010 to December 2014 for children 611 years of age admitted with a primary diagnosis, based on International Classification of Diseases, $9^{\text {th }}$ revision (ICD-9), of acute asthma exacerbation or status asthmaticus (ICD-9 codes 493, 493.01, 493.02, 493.1, 493.11, 493.12, 493.9, 493.91, or 493.92). Admissions were excluded if patients had other cardiac, pulmonary, or neuromuscular disorders that impact breathing and transfer hospitalizations.

We queried demographic information for patients, asthma medications used, and respiratory support measures provided for each admission. Intraclass correlations (ICC) were estimated with random intercept logistic regression models using Stata 13.1 (StataCorp LP, College Station, TX). Shrinkage estimates from the mixed effects models were reported to account for variability due to hospitals with small sample sizes.

In total, 5,330 PICU admissions for asthma across 40 hospitals were included in the analysis. During the study period, PICU admissions for asthma per hospital ranged from 21 to 462 (Median=115, IQR=46 to 160 ). In total, $61 \%$ of patients were male with median age of 8 years old. Black race comprised $57 \%$ of the population with $23 \%$ white, $19 \%$ other, and $12 \%$ Hispanic ethnicity. The average length of hospitalization was 3 days, while the average length of stay in the PICU was 1 day. Medicaid was the primary payer for $79 \%$ of admissions, while HMO and PPO each comprised $10 \%$ of admissions. $99.9 \%$ of patients were discharged, while $0.1 \%$ ( 7 patients) died during hospitalization. Characteristics of admitted patients are shown in Table E1 (Online Repository).

For each treatment measured, rates of treatment use varied significantly across hospitals (all $\mathrm{p}<0.001$ ). For PICU admissions, hospital level variability explained a considerable amount of the total variability of each treatment method, with ICCs ranging from 0.14 for magnesium sulfate to 0.71 for helium oxygen (heliox). Table I demonstrates the percentile of all PICU admissions using a specific treatment modality in hospitals at the $25^{\text {th }}, 50^{\text {th }}$, and $75^{\text {th }}$ percentile. Ipratropium bromide and magnesium sulfate were the most common treatments, but between-hospital variability explained $52 \%$ of the total ipratropium bromide variability compared to only $14 \%$ of the total magnesium sulfate variability. Terbutaline was used less frequently than both ipratropium bromide and magnesium sulfate. Heliox was used less frequently than all other therapies, with $71 \%$ of the variability explained at the hospital level. Use of modes of respiratory support were also variable across hospitals, including NPPV (includes CPAP and BiPAP) and mechanical ventilation. BiPAP was used more 
frequently than mechanical ventilation for all PICU admissions, and mechanical ventilation had greater variability of use among hospitals studied. The PHIS database does not allow determination of the sequence that medications or therapies were given. Figure 1 demonstrates treatment variation across hospitals for PICU admissions.

Our analysis focused on medications beyond standard frontline therapies (short-acting beta $2^{-}$ agonist, corticosteroids, and oxygen), as these medications are widely accepted and used in the management of moderate to severe asthma exacerbations. For PICU admissions, use of all medications and respiratory support measures varied widely across hospitals, highlighting the lack of uniformity in approaching critically ill patients with asthma. The implications of these treatment variations across hospitals are not entirely known, but may lead to variable patient outcomes. Given the level of acuity of patients who are admitted to the PICU with the highest potential for morbidity and mortality, this analysis highlights the need for more evidence-based standardized approaches to treatment.

We focused on hospitalizations involving admission to a PICU as we were interested in more severe asthma exacerbations which may require medications that are not guideline-based.

We focused our analysis on ages 6-11, excluding ages 2-5 and children 12 and over. Asthma management may differ slightly in each age group, which could skew the data. Utilizing the multicenter national PHIS database to analyze variability in PICU practice offers the great advantage of allowing for evaluation of discrete trends of what would otherwise be rare events for individual institutions. However, determining healthcare trends by administrative data has several limitations. Treatments delivered are based on billing data, so errors in data entry or coding may lead to incorrect data; however, the large sample size should minimize the effect of any small aberrations in coding. Additionally, PICU admission criteria may vary from center to center based on experience and resources, similar to the level of acuity of a patient that seeks care. We attempted to minimize this potential bias by excluding hospital transfers and significant patient comorbidities.

We demonstrated that medication use and respiratory support measures vary greatly between institutions, especially medications beyond frontline therapies including corticosteroids, albuterol, and oxygen. Treatments used for severe asthma exacerbations are quite variable between hospitals. Future analyses should determine outcomes based on treatment variations for asthma exacerbations. Research efforts should focus on the development of guidelinebased management of severe asthma exacerbations.

\section{Supplementary Material}

Refer to Web version on PubMed Central for supplementary material.

\section{Acknowledgments}

Financial Support: Meredith Dilley is funded by NIH grant T32HD0757270. William Sheehan is funded by K23AI104780. Jonathan Gaffin is funded by NIH K23AI106945. Wanda Phipatanakul is funded by NIH grant K24AI106822. Carter Petty is supported by NIH grant U01 AI 110397. 


\section{Abbreviations}

$\begin{array}{ll}\text { PICU } & \text { pediatric intensive care unit } \\ \text { PHIS } & \text { Pediatric Health Information System } \\ \text { ICD-9 } & \text { International Classification of Diseases } \\ \text { NIPPV } & \text { Non-invasive positive pressure ventilation } \\ \text { BiPAP } & \text { Bilevel positive airway pressure } \\ \text { CPAP } & \text { Continuous positive airway pressure } \\ \text { ICC } & \text { intraclass correlation }\end{array}$

\section{References}

1. Everhart RS, Fiese BH. Asthma severity and child quality of life in pediatric asthma: a systematic review. Patient Educ Couns. 2009; 75:162-168. [PubMed: 19036553]

2. Friedman B, Berdahl T, Simpson LA, McCormick MC, Owens PL, Andrews R, Romano PS. Annual report on health care for children and youth in the United States: focus on trends in hospital use and quality. Acad Pediatr. 2011; 11:263-279. [PubMed: 21640682]

3. Pyle RC, Divekar R, May SM, Narla N, Pianosi PT, Hartz MF, Ott NL, Park MA, McWilliams DB, Green JA, Despins KN, Joshi AY. Asthma-associated comorbidities in children with and without secondhand smoke exposure. Ann Allergy Asthma Immunol. 2015; 115:205-210. [PubMed: 26208757]

4. Black MH, Zhou H, Takayanagi M, Jacobsen SJ, Koebnick C. Increased asthma risk and asthmarelated health care complications associated with childhood obesity. Am J Epidemiol. 2013; 178:1120-1128. [PubMed: 23924576]

5. Fitzpatrick AM, Teague WG, Meyers DA, Peters SP, Li X, Li H, Wenzel SE, Aujla S, Castro M, Bacharier LB, Gaston BM, Bleecker ER, Moore WC. National Institutes of Health/National Heart L, Blood Institute Severe Asthma Research P. Heterogeneity of severe asthma in childhood: confirmation by cluster analysis of children in the National Institutes of Health/National Heart, Lung, and Blood Institute Severe Asthma Research Program. J Allergy Clin Immunol. 2011; 127:382-389. e381-313. [PubMed: 21195471]

6. Asthma GIf. Global Initiative for Asthma: Global Strategy for Asthma Management and Prevention. 2015; 20152015

7. National Asthma E, Prevention P. Expert Panel Report 3 (EPR-3): Guidelines for the Diagnosis and Management of Asthma-Summary Report 2007. J Allergy Clin Immunol. 2007; 120:S94-138. [PubMed: 17983880]

8. Tsai CL, Sullivan AF, Gordon JA, Kaushal R, Magid DJ, Blumenthal D, Camargo CA Jr. Quality of care for acute asthma in 63 US emergency departments. J Allergy Clin Immunol. 2009; 123:354361. [PubMed: 19070357]

9. Bratton SL, Odetola FO, McCollegan J, Cabana MD, Levy FH, Keenan HT. Regional variation in ICU care for pediatric patients with asthma. J Pediatr. 2005; 147:355-361. [PubMed: 16182675] 

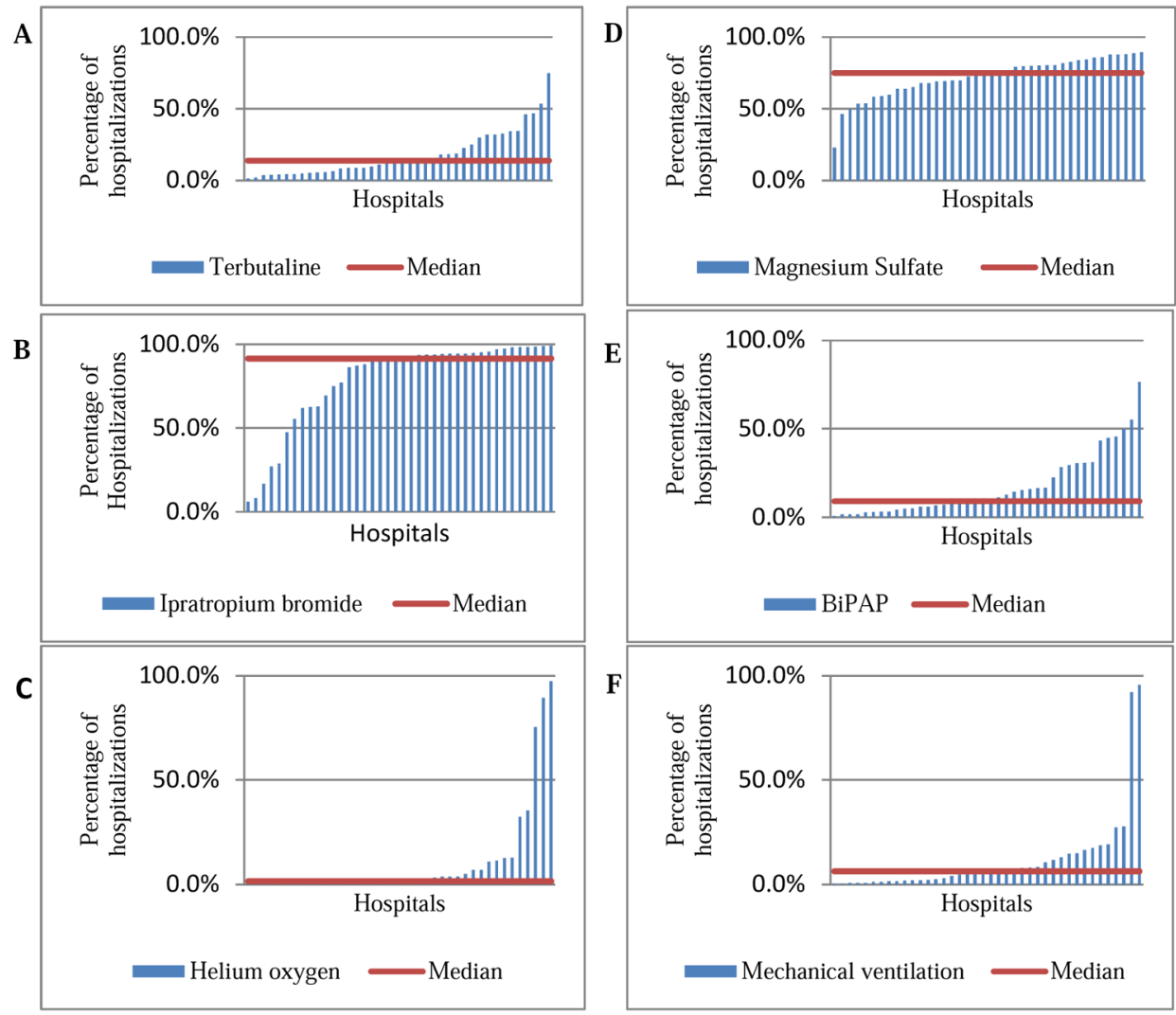

Figure 1.

Variation in use of medication and respiratory support measures across hospitals for PICU admissions, 2010-2014. Each bar represents a single U.S pediatric hospital. Use of medication for each hospital in the database was reported after using shrinkage estimates in order to account variability due to hospitals with small sample sizes. A. Terbutaline B. Ipratropium Bromide C. Helium Oxygen D. Magnesium sulfate E. BiPAP F. Mechanical ventilation 


\section{Table I}

Variation in Medication and Treatment Use between Hospitals, 2010-2014

\begin{tabular}{|l|l|l|l|l|}
\hline & \multicolumn{4}{|c|}{ Percentage of hospitals using treatment, PICU admissions } \\
\hline Treatment & $\mathbf{2 5}^{\text {th }}$ ile & $\mathbf{5 0}^{\text {th }} \%$ ile & $\mathbf{7 5}^{\text {th }}$ ile & ICC [95\% CI] \\
\hline Terbutaline & 5.5 & 13.8 & 26.2 & $0.31[0.22,0.42]$ \\
\hline Ipratropium bromide & 67.8 & 91.4 & 95.0 & $0.52[0.40,0.64]$ \\
\hline Magnesium sulfate & 64.7 & 74.9 & 81.8 & $0.14[0.09,0.22]$ \\
\hline Heliox & 0.2 & 1.5 & 7.0 & $0.71[0.56,0.82]$ \\
\hline BiPAP & 5.1 & 9.2 & 28.7 & $0.37[0.26,0.50]$ \\
\hline Mechanical ventilation & 2.0 & 6.3 & 13.4 & $0.52[0.38,0.65]$ \\
\hline
\end{tabular}

Use of medication for each hospital in the database was reported after using shrinkage estimates in order to account variability due to hospitals with small sample sizes. 